\title{
Clinical Evaluation and Orodental Status in a Group of Elderly Institutionalised Patients
}

\author{
Massimo Corsalini1 ${ }^{*}$, Daniela Di Venere ${ }^{1}$, Gianluca Stefanachi' ${ }^{1}$, Silvio Tafuri², \\ Francesco Pettini ${ }^{1}$ \\ ${ }^{1}$ Department of Odontostomatology and Surgery, University of Bari, Bari, Italy \\ ${ }^{2}$ Department of Biomedical Sciences and Human Oncology, University of Bari, Bari, Italy \\ Email: $\underline{\text { massimo.corsalini@uniba.it }}$
}

Received 4 May 2014; revised 5 June 2014; accepted 26 June 2014

Copyright (C) 2014 by authors and Scientific Research Publishing Inc.

This work is licensed under the Creative Commons Attribution International License (CC BY). http://creativecommons.org/licenses/by/4.0/

(c) (i) Open Access

\begin{abstract}
$10 \%$ of elderly patients are functionally dependents and they therefore need permanent assistance. Orodental alterations may evolve into a pathological state in elderly people, which is increasing in the recent decades. The current study analysed institutionalized patients in the district of Bari (Southern Italy), who have been so far monitored. We assessed 125 elderly institutionalized patients. The assessment has been carried out by an assessment questionnaire aiming at evaluating the patient's psychophysical health status, objective intraoral test and prosthetic rehabilitations. About $\mathbf{9 0 \%}$ of enrolled patients reported a good general health status. The main dental problems are due to the complete lack of specific prevention and treatment programs, together with handicap, presence of systemic diseases and medicines taken. The level of oral hygiene is poor and the conditions of the residual dental elements are precarious because of root caries and periodontal problems. Prostheses are usually old (on average 15) and appear scarcely retentive and unstable. We believe in the need for specific interventions aiming at the various issues emerging from the present study, so as to achieve a smaller prevalence of dental loss, periodontal disease and caries. These relatively simple interventions are now lacking because of the non-demand of treatment from patients and for economical reasons.
\end{abstract}

\section{Keywords}

Institutionalised Hospital Care, Oral Health, Oral Cleanliness, Treatment Needs

\section{Introduction}

The United Nations (UN) Second World Assembly on Ageing (Madrid, 8-12 April 2012) pointed out that the "Corresponding author.

How to cite this paper: Corsalini, M., Venere, D.D., Stefanachi, G., Tafuri, S. and Pettini, F. (2014) Clinical Evaluation and Orodental Status in a Group of Elderly Institutionalised Patients. Advances in Aging Research, 3, 199-207.

http://dx.doi.org/10.4236/aar.2014.33028 
number of elderly people (persons aged $>64$ years) would increase from $10 \%$ of world population in 1998 , to $15 \%$ in 2050 .

Age progression engenders various changes in human organism. The most frequent age stomatognathic apparatuses are dental caries, loss of periodontal insertion, loss of dental elements and bone resorption, reduced strength of the masticatory muscles, and TMJ problems.

Another frequent situation affecting elderly people is the loss of molars which are frequently extracted because of caries and/or periodontitis; the consequent outcome is a SDA (Shortened Dental Arch). This condition is strictly correlated to the phenomenon of the resorption of residual bone crest, a chronic and progressive process [1].

About $10 \%$ of the over 65 populations may be considered "functionally dependant" because they are either institutionalized (5\%) or receiving care in long term hospitalization centres (5\%): in both cases, patients are not self-sufficient and are not able to live on their own.

The objective of the present study is to provide an outline of the current situation of the orodental care in institutionalised elderly patients in the district of Bari, an area where any specific monitoring has been so far done, also in order to schedule potential odonto-prosthetic interventions aiming at producing real beneficial outcomes.

Institutionalised patients reported odonto-prosthetic problems that are relatively easy to solve, but they still do not have easy access to dental care because of organizational and economical reasons.

\section{Materials and Methods}

The present study is a part of a project which involved several Italian Universities, in particular the Dental Clinics of the University of Turin, Ferrara, Genoa, Brescia and Bari. The main aim was to profile the general status of orodental health of institutionalised patients. We used an assessment test and patients signed a written explicit consent.

Authorization from the Ethic Committee of the Odontostomatology Department of the University of Bari was asked and obtained.

125 patients (65 women and 60 men) were examined in four different care homes in the district of Bari.

The patients underwent a comprehensive assessment in the form of:

1) Patient's personal data.

2) Mental status assessment: patients have to answer questions regarding their orientation skills in place and time, and their capability to sort out basic calculations [2].

3) Patient's psychological assessment: in order to frame the patient's emotional status, the patients were asked to express themselves about the following feelings: sadness, pessimism, sense of failure and guilt, dissatisfaction, self-devaluation, self-aggressiveness, social retirement, indecisiveness, self-opinion change, working difficulty, tiresomeness, anorexia [3].

4) General anamnesis (pathological remote and near): we interviewed the patients about used drugs, past and present pathologies, surgical interventions, blood pressure values, height, weight, urine output. In particular, we considered the duration of disease course (arterial hypertension, cardiopathy, chronic bronchitis, vascular and neurological diseases, gastroesophageal reflux, diabetes, neoplasia, poliomyelitis, hepatitis A, B, C, D, AIDS, kidney diseases) or between surgical interventions undergone so far.

5) Assessment of the patient's working skills [4] and his/her sleep disorder [5].

It is composed of questions to be asked the patient for, in order to know his judgment, sometimes expressed in numbers, about:

a) Ability to accomplish normal, everyday activities (1 = very good, 6 = very bad);

b) Snoring (modality and frequency);

c) Night respiratory problems;

d) Sleep interference while driving;

e) Sleep disorder (difficulty to sleep and frequent night awakenings);

f) Sleeping position and headache onset at the awakening.

6) AMSP assessment:

We tried to acquire the patient's subjective assessment of his nutritional status, his capability to chew and taste food, by a prosthesis or not, deglutition and xerostomia problems, prosthesis frequency of use (never, always, the whole day, during meals, at night) and its stability during chewing. 
7) MNA (Mini Nutritional Assessment) [6]:

It is divided into four sections:

a) Anthropometric measurements: BMI; circumference at mid arm and gastrocnemius, weight loss in the last three months.

b) Global assessment of self-sufficiency status, medicine consumption, acute diseases in the last three months, mobility, neuropsychological problems, presence of excoriations or cutaneous ulcers.

c) Diet information (quality and quantity of meals, potential nutritional problems due to appetite deficit, digestion problems, masticatory apparatus and deglutition problems; liquids consumption; nutritional self-sufficiency).

d) Patient's subjective assessment of his health status as compared to peers and of his/her nutritional status.

Each item was given a numeric value so that at the end of the MNA, we could obtain a basic score (sorted out from the total sum) on the basis of which the patient could be defined: well-fed (score higher or equal to 24), at hyponutrition risk (between 17 and 23.5), underfed (less or equal to 17).

8) General and soft tissues file:

We collected information about smoking and drinking, dental check-ups frequency and the willingness to undergo dental care.

The presence of lesions of the oral soft tissues was also assessed (traumatic lesions from prosthesis, erosiveblistering diseases, candidosis, tumour lesions, herpetic stomatitis, leukoplakia, lichen, herythroplakia, aphthous stomatitis, Burning Mouth Syndrome (BMS) noise or Temporomandibular Joint (TMJ) pain.

9) Odontoiatric and prosthetic file:

Matter of examination was: oral hygiene degree, conditions of the residual dental elements (number, presence of root and/or coronal caries, periodontal problems), number of restored teeth with fix prosthesis, the patient's edentulous status (partial or total), the conditions of complete denture (retention, stability, keeping, hygiene, vertical dimensions, the patient's and the odontologist's esthetical judgement, patient's satisfaction, age and material of the prosthesis, wearing and allergies), the date of the last prosthetic control.

Finally, the necessity degree of an odonto-prosthetic intervention was set as well as the need for an OPT.

Completed questionnaire were computerized in a database created by File Maker Pro and analysed by Microsoft Excel software.

\section{Results}

After each patient had undergone the assessment, this is the obtained outcome.

The average age was 81.5 for women and for men, 78.9.

$34 \%$ of women was single, $22 \%$ married, $40 \%$ widowed, $4 \%$ separated; for men, this figures were $32 \%$ single, $26 \%$ married, $37 \%$ widowed and the remaining $5 \%$ separated.

$34 \%$ of women and $28 \%$ of men was unschooled; $40 \%$ of women and $45 \%$ of men attended elementary school (the first two years), $18 \%$ of female and $15 \%$ of men had got middle school diploma; finally, $8 \%$ of women and $10 \%$ of men achieved high school diploma, and $2 \%$ of male graduated.

The average mental status score among women was 6.2 and 7.1 among men.

Regarding the patient psychological assessment, most of women felt sad and melancholic, but none of them claimed to be discouraged about their future or dissatisfied with their past. None of the women had any sense of guilt or felt self-disappointed, nor they revealed a tendency to social retirement, but a good number of them claimed to suffer from a reduced work capability.

The data regarding men's emotional status, attested that most of them did not feel particularly sad or discouraged about their future, neither they were dissatisfied nor disappointed about their past nor they felt any sense of guilt. They furthermore did not reveal any self-aggressiveness tendency.

Almost none of the patients reveal any difficulty in relating with other people or in decision-making. On the contrary, a reduction in their working capability emerged.

We outlined the general health conditions of each patient.

About women, only 9 (13.8\%) patients did not take any medicine whereas the other patients revealed a predominance of treatments for heart diseases, hypertension and anxious-depressive statuses.

Among men, ten (16.7\%) did not take any medicine whereas the other ones mainly used medicines for heart pathologies and hypertension.

Previous diseases were almost never documented nor were they referred to by patients. The predominant pa- 
thologies were mainly chronic: diabetes mellitus, bronchitis, hypertension, cardiopathy and dementias.

Patients were asked different questions in order to assess their working capability and the potential presence of sleep disorders.

In women, the capability to accomplish activities at work or in their everyday life was mainly classified as acceptable and no drowsiness interfering with the aforementioned activities was observed.

The situation outlined by men, provided less marked data. The patients' answer about their capability to execute normal everyday activities were almost homogeneously distributed throughout all the possible ratings (from very good to very bad), whereas a higher rate of drowsiness interference with normal everyday activities emerged.

The patient's subjective assessment of his/her nutritional status was positive, both for women and men; in fact no loss of appetite or weight was noticed. The majority of women complained about having some troubles in chewing, both because of the lack of teeth and because of an incongruous prosthesis; they in fact reported to avoid eating some kinds of food, especially dry food.

Any decrease in their tasting capability with or without prosthesis was noticed.

Male patients, though claiming to have difficulty in chewing, both because of their teeth and because of their prosthesis, did not avoid any kind of food.

The patients' taste sensation did not appear reduced even when using their prosthesis.

None of the patients complained about stability or interferences of their prosthesis.

Finally, in regard to patients' prosthesis use habits, the most of women claimed to use it even at night, whereas the majority of men only during the day.

The mean value of MNA test was 22.6 for women, which corresponds to a hyponutrition risk status; the mean value for men was 24 , indicating an adequate nutrition.

Regarding voluptuary habits, among women, $2 \%$ smoked (less than 10 cigarettes a day) and 26\% regularly had alcoholic drinks (wine and/or beer).

Among men instead, 36\% claimed to be former smokers and 8\% smokers (smoking on average 14.4 cigarettes a day). $28 \%$ regularly had alcoholic drinks (wine and/or beer).

Regarding the frequency of odonto-prosthetic controls, $31 \%$ of women claimed not to have undergone any and the remaining $69 \%$ only rarely.

$17 \%$ of men had never undergone any control and the remaining $83 \%$ only rarely.

Oral lesions, inspected by clinical examination, were all detected in those patients who used total mobile prosthesis (17 women and 21 men).

Particularly, 7 women out of 17 were affected by candidosis and 10 of them revealed traumatic prosthesisrelated lesions; one of the men revealed traumatic prosthesis-related lesions, one was affected by candidosis and another one had a benignant, relapsing neoplasia of the oral floor, detected and treated in the past; a man revealed glossitis losangica mediana and another one manifested a patina of accumulation on his lingual dorsum with disepithelized area due to a probable phungine onset.

Sintomatology and clinical signs of TMJ pathologies were observed. These were found only in two male patients.

\section{Odontoiatric and Prosthetic File}

The oral hygiene level detected both in women and in men with natural teeth was poor (presence of plaque and tartar).

Among women, the overall analysis of the dental situation revealed that: $43 \%$ were edentulous in both lower and upper arch, $16 \%$ were edentulous in the upper arch and partially edentulous in the lower arch, and $15 \%$ were edentulous in the lower arch and partially in the upper one, whereas $26 \%$ were partially edentulous in the upper and lower arch (Graph 1(a)).

The main problems concerning residual teeth (average value of elements per arch per patient: up 6.9, low 9.3) were, on the upper arch, root caries for $35 \%$, coronal caries for $29 \%$, periodontal problems for $30 \%$ (6\% any problems at all).

As far as the lower arch is concerned, $28 \%$ of the total residual teeth revealed root caries; $26 \%$ coronal caries and 23\% periodontal caries (23\% any problems at all) (Graph 2(a)).

$7 \%$ of upper teeth and $3 \%$ of lower residual ones had been restored with fixed prosthesis. 


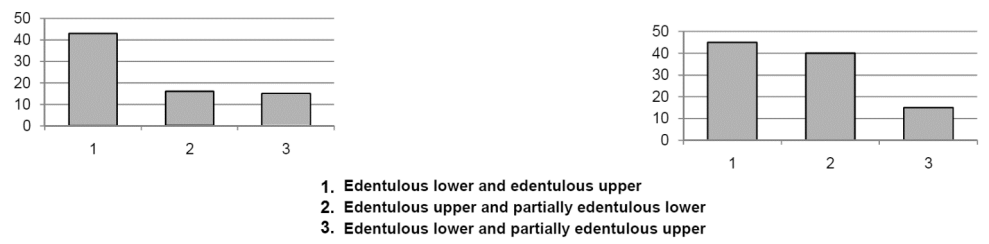

Graph 1. Dental status.

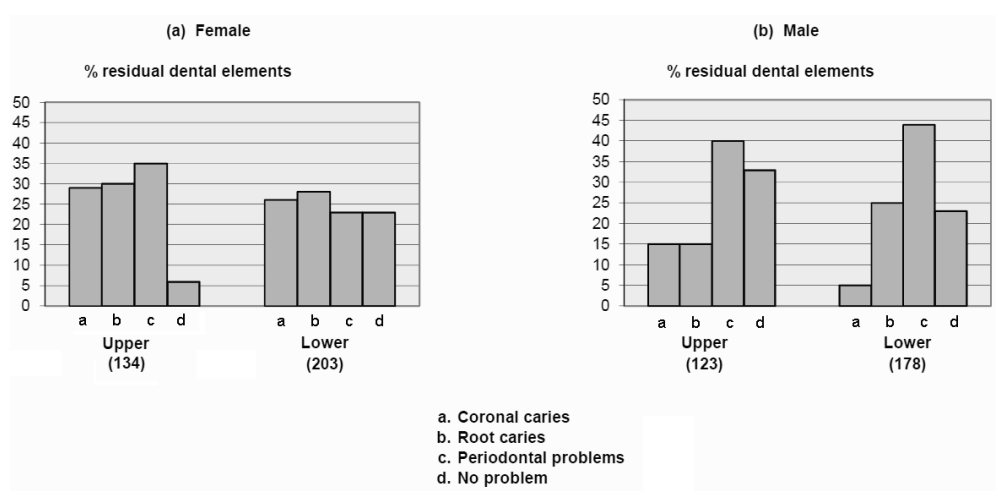

Graph 2. Conditions of the residual dental elements.

Regarding total edentulous female patients, $46 \%$ did not have any prosthesis, $8 \%$ had only upper prosthesis while the remaining $46 \%$ had upper and lower prosthesis.

The partially edentulous female patients outlined the following situation: $10 \%$ were partially edentulous in the lower arch without prosthesis, $10 \%$ were partially edentulous both in the upper and in the lower arch with prosthesis, $60 \%$ were partially edentulous in both arches without any prosthesis, $10 \%$ had only an upper prosthesis, $5 \%$ were partially edentulous in the upper arch without prosthesis and $5 \%$ were with prosthesis.

The most of prosthesis were made of acrylic material. All the partial removable prostheses were made of alloyacrylic resin and the fixed prosthesis were made of gold alloy and resin.

Almost all the prosthesis appeared worn out, nevertheless any prosthesis-related allergic rash was observed.

The prosthesis average age was 15 years, whereas the last prosthetic control dated back to 9 years before.

The analysis of the prosthesis allowed us to observe that the retention of upper complete denture was on average good, while the retention of lower complete denture was mainly poor.

As far as stability is concerned, upper prostheses were all sufficiently stable; the lower ones were so only partially. The keeping of total lower and upper prosthesis, was scarce and so was the hygiene level. Vertical dimensions scored average outcomes.

The patient's satisfaction level and esthetical judgment were good throughout all cases, whereas the operator's ones were almost always acceptable.

On the basis of all the collected data, $70 \%$ of patients revealed a severe need for prosthetic intervention, $13 \%$ revealed a mild need and the remaining $17 \%$ revealed a medium need (Graph 3).

Finally, in $85 \%$ of the cases an OPT was considered necessary.

The overall analysis of the dental situation of male patients provided the following data: $40 \%$ of patients had upper and lower edentulous jaws, $15 \%$ was edentulous in the upper jaw and partially edentulous in the lower jaw, 45\% was partially edentulous in both jaws (Graph 1(b)).

Residual teeth in the arches (the average value for the upper arch was 4.5 and for the lower arch was 6.7) revealed these problems: root caries in $15 \%$ of the total residual upper teeth and in $25 \%$ in the lower ones; coronal caries in $15 \%$ of the residual upper teeth and in $5 \%$ of the lower ones; periodontal problems in $40 \%$ of upper teeth and $44 \%$ in the lower teeth (33\% of total residual upper teeth and $23 \%$ of the lower ones did not reveal any problem) (Graph 2(b)).

$26 \%$ of total residual upper teeth had been restored with fixed prosthesis whereas the lower ones were $4 \%$. 


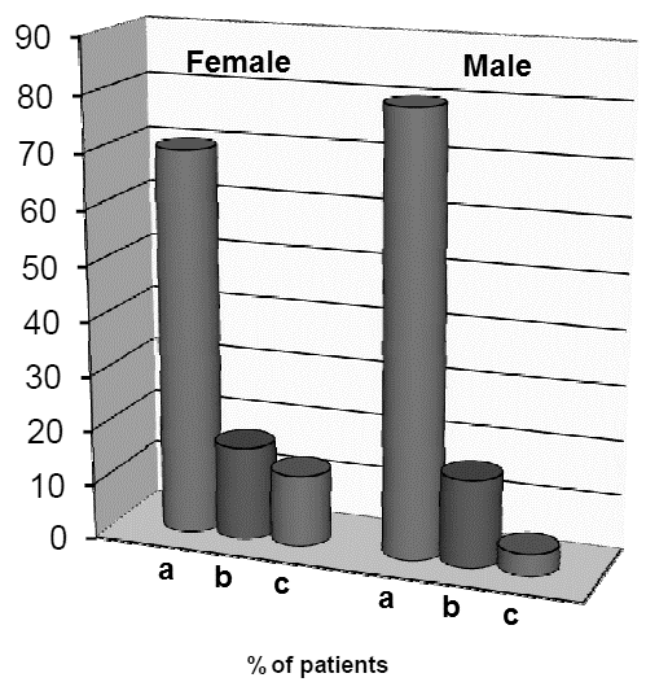
a. Mild need
b. Medium need
c. Severe need

\section{Graph 3. Need for prosthetic intervention.}

$60 \%$ of edentulous patients did not have any prosthesis, $26 \%$ had both prosthesis and the remaining $14 \%$ had only the upper one.

Regarding partial edentulism, 55\% of the patients were partially edentulous in the upper arch and did not have lower prosthesis, $13 \%$ were partially edentulous in the lower arch without prosthesis and the remaining $32 \%$ was equally divided into three groups:

- Partially edentulous in the lower arch with prosthesis;

- Partially edentulous in the lower and upper arch with both prosthesis;

- Partially edentulous in the lower and upper arch with only an upper prosthesis and only a lower prosthesis.

All total prosthesis were made of acrylic resin, all the partial prosthesis were made of alloy and acrylic resin, fixed prosthesis were made of gold alloy and resin.

$65 \%$ of prosthetic products appeared worn out, however we did not observe any allergic rash. The prosthesis average age was 16.2 years, the last prosthetic control dated back to 13, 5 years before.

The inspection of the prosthesis revealed that the retention and stability of total upper prosthesis were usually acceptable, while the lower ones were not.

The keeping and the hygiene of the prosthesis, either upper or lower, were not acceptable too.

Vertical dimensions fell within the average standards.

The esthetic judgment and satisfaction degree expressed by patients were good; the operator's ones were acceptable.

According to this data, also for male patients, there was a severe need for odonto-prosthetic intervention in $80 \%$ of the cases, medium need in 16\%, and mild need in 4\% (Graph 3). For 93\% of patients, an OPT was necessary.

\section{Discussion}

Nowadays elderly people have a precarious dental health and few natural teeth. The main issue is given by the high prevalence of root caries and by insufficient oral hygiene [7] due to their handicap, coexistent systemic diseases and medicines taken, but, above all, to the complete lack of specific prevention and care programmes. We furthermore have to take into consideration the physiological change in the stomatognathic apparatus inevitably engendered by ageing: not only the change affecting dental tissues and oral mucosa, but also the change relative to the musculoskeletal system. In fact, the top occlusive strength, produced by masticatory muscles, is reached at the age of 35 in women and 45 in men, but it is doomed to inexorable decline along with ageing [8] [9]. 
The situation is even more complex in functionally dependent elderly people who represent $10 \%$ of population over 65 years. Their average age is $82 ; 71 \%$ of them are women of whom $62 \%$ are widows. They reveal variable degrees of physical and psychological disability [10], they take different medicines (on average 3.2 per person), live in solitude conditions and they mostly end their lives in care homes [11].

These subjects, like everybody else, undergo physiologic change due to ageing but they also display a higher risk to contract local and systemic pathologies and to display psychiatric problems [10]. Aligning with all this, we should be take into consideration further deficit, physical and mental, related to lack of assistance, socioeconomic factors, social isolation etc.

Different studies has been conducted in order to get further detailed knowledge about the orodental conditions of the institutionalised patient, and they all showed a high prevalence of periodontal diseases [12], root caries [13], mucosa prosthesis-related [14]-[16], lesions, and the urgent need for corrections or substitution of current prosthesis [12]-[18].

The present study too aimed at outlining the mental and physical profile (with special regards to oral health conditions) of this category, highlighting its most evident issues. The main profiles observed in the 125 patients are:

- Edentulous patient in the upper and lower arch with both prostheses;

- Edentulous patient in the upper and lower arch without any prosthesis;

- Partially edentulous patient in the upper and lower arch without any prosthesis.

The hygiene level is poor and the conditions of the residual dental elements are often precarious because of the presence of root caries and/or periodontal problems.

The prosthesis, when present, is usually old (on average 15 years) and appears worn out, scarcely retentive and unstable. The hygiene level and keeping are poor and this is probably due to the fact that the patient rarely, or even never, undergoes prosthetic controls.

Ultimately, the overall condition of institutionalised patients is good since the institute cares for the patient's primary needs and medical assistance, at least for what concerns his/her main pathologies [19] [20].

All this notwithstanding, serious deficiencies emerge in regard to the demand for odontoiatric controls and care, which is proved by the precarious odonto-prosthetic situation of most patients.

\section{Conclusions}

The results of the present study basically confirm what is reported in literature and therefore allow for a truthful outline of the orodental and, more summarily, physical and mental conditions of institutionalised patients.

Such interventions would allow for an improvement of elderly patients' present orodental conditions achieving a less precarious future situation and a lower prevalence of dental loss, periodontal diseases and caries.

It should be pointed out that even though the necessary interventions are relatively simple, the main issue remains the patients' lack of demand for care [21].

Actually, the present situation is partly justified by their psychophysical conditions which lead them both to ignore their precarious orodental state and not to report it.

Patients in care homes receive only emergency care and it is the staff who arbitrarily decides whether the patient will be actually visited by a dentist [22].

Considering what has been so far highlighted, it is clear the need for specific programmes [23] is based on:

- Organization;

- Communication;

- Training.

Basically, care home staff needs to be aware of the issues and to be involved in the project, whereas the odontologist will be in charge of care and coordination.

The abovementioned programmes consist of different phases:

- Interventions aiming at improving the patient's general health status and, more specifically, his/her nutritional status.

- Attempts to preserve natural teeth by conservative therapy of carious lesions, surgical periodontal therapy and hygiene controls so as to halt the periodontal disease's progression [24].

- Dental extractions: dental elements are often in such precarious conditions that they cannot be treated.

- Prosthetic rehabilitation: it is of primary importance to carefully analyse the patient's situation in order to 
select the most suitable solution.

- Management of prosthetic-related stomatitis.

- Prevention measures, through a system of controls and specific recalls, aiming at the upkeeping of a correct oral hygiene and at an adequate and periodical maintenance of prosthesis [25] [26].

These programmes are undoubtedly the most suitable solution to orodental problems in elderly institutionalised patients since they match preventive and therapeutic measures. The main issue is nonetheless the factual actualization of these measures, mainly because of the high cost they entail.

We should also take into account the fact that elderly population is steadily growing and that most of the subjects living in care homes suffer from poor economical conditions which are barely sufficient to fulfil basic necessities.

It can be therefore inferred that, if these prevention and orodental therapy programmes are implemented, society will also happen to bear their cost, causing a highly negative cost/benefit ratio.

\section{References}

[1] Atwood, D.S. and Coy W.A. (1971) Clinical, Cephlalometric and Densitometric Study of Reduction of the Residual Ridges. Journal of Prosthetic Dentistry, 26, 280-295 http://dx.doi.org/10.1016/0022-3913(71)90070-9

[2] Pfeiffer, E. (1975) A Short Portable Mental Status Questionnaire for the Assessment of Organic Brain Deficit in Elderly Patients. Journal of the American Geriatrics Society, 23, 433-441.

[3] Yesavage, J.A., Brink, T.L., Rose, T.L. Lum, O., Huang, V., Adey, M. and Leirer, V.O. (1983) Development and Validation of a Geriatric Depression Screening Scale: A Preliminary Report. Journal of Psychiatric Research, 17, 37-49. http://dx.doi.org/10.1016/0022-3956(82)90033-4

[4] Katz, T.F. (1963) A.D.L. Activities of Daily Living. Journal of American Medical Association, 185, 914-919. http://dx.doi.org/10.1001/jama.1963.03060120024016

[5] Buysse, D.J., Reynolds, C.F., Monk, T.H., Berman, S.R. and Kupfer, D.J. (1989) The Pittsburgh Sleep Quality Index: A New Instrument for Psychiatric Practice and Research. Psychiatry Research, 28, 193-213. http://dx.doi.org/10.1016/0165-1781(89)90047-4

[6] Ferreira, L.S., Nascimento, L.F. and Marucci, M.F. (2008) Use of the Mini Nutritional Assessment Tool in Elderly People from Long-Term Institutions of Southeast of Brazil. The Journal of Nutrition Health and Aging, 12, 213-217.

[7] Katz, R.V., Neely, A.L. and Morse, D.E. (1996) The Epidemiology of Oral Diseases in Older Adults. In: HolmPedersen, P. and Loe, H., Eds., Textbook of Geriatric Dentisty, Munksgaard, Copenhagen, 263-301.

[8] Helkimo, E., Carlsson, G.E. and Helkimo, M. (1977) Bite Force and State of Dentition. Acta Odontologica Scandinavica, 35, 297-303. http://dx.doi.org/10.3109/00016357709064128

[9] Bakke, M., Holm, B., Jensen, B.L., Michler, L. and Möller, E. (1990) Unilateral, Isometric Bite Force in 8 68-YearOld Women and Man Related to Occlusal Factors. Scandinavian Journal of Dental Research, 98, 149-158.

[10] Kossioni, A.E., Kossionis, G.E. and Polychronopoulou, A. (2012) Oral Health Status of Elderly Hospitalised Psychiatric Patients. Gerodontology, 29, 272-283. http://dx.doi.org/10.1111/j.1741-2358.2012.00633.x

[11] Ettinger, R.L. (1996) Oral Health Care Programs for Homebound People, Nursing Home Residents and Elderly in Patients. In: Holm-Pedersen, P. and Loe, H., Eds., Textbook of Geriatric Dentistry, Munksgaard, Copenaghen, 536-560.

[12] Stuck, A.E., Chappuis, C., Flury, H. and Lang, N.P. (1989) Dental Treatment Needs in a Elderly Population Referred to a Geriatric Hospital in Switzerland. Community Dentistry and Oral Epidemiology, 17, 267-272. http://dx.doi.org/10.1111/j.1600-0528.1989.tb00631.x

[13] Vigild, M. (1989) Dental Caries and the Need for Treatment among Institutionalised Elderly. Community Dentistry and Oral Epidemiology, 17, 102-105. http://dx.doi.org/10.1111/j.1600-0528.1989.tb00598.x

[14] Vigild, M. (1987) Oral Mucosal Lesions among Institutionalized Elderly in Denmark. Community Dentistry and Oral Epidemiology, 15, 309-313. http://dx.doi.org/10.1111/j.1600-0528.1987.tb01741.x

[15] Wilkiesen, C., Samaranayake, L.P., MacFarlane, W., Lamey, P-J. and MacKenzie, D. (1991) Oral Candidosis in the Elderly in Long Term Hospital Care. Journal of Oral Pathology \& Medicine, 20, 13-16. http://dx.doi.org/10.1111/j.1600-0714.1991.tb00880.x

[16] Budz-Jorgensen, E., Mojon, P., Rentsch, A., Roehrich, N., von der Muehll, D. and Baehni, P. (1996) Caries Prevalence and Associated Predisposing Conditions in Recently Hospitalized Elderly Persons. Acta Odontologica Scandinavica, 54, 251-256. http://dx.doi.org/10.3109/00016359609003533

[17] Vigild, M. (1987) Denture Status and Need for Prosthodontic Treatment among Institutionalised Elderly in Denmark. Community Dentistry and Oral Epidemiology, 15, 128-133. http://dx.doi.org/10.1111/j.1600-0528.1987.tb00499.x 
[18] Corsalini, M., Grassi, R., Di Venere, D., Carella, M., Caprio, S. and Covelli, M. (2004) Prosthetic Rehabilitation of Edentulous Patients after Stroke. Minerva Stomatologica, 53, 101-109.

[19] Schimmel, M., Leemann, B., Christou, P., Kiliaridis, S., Schnider, A., Herrmann, F.R. and Müller, F. (2011) Oral Health-Related Quality of Life in Hospitalised Stroke Patients. Gerodontology, 28, 3-11.

http://dx.doi.org/10.1111/j.1741-2358.2009.00330.x

[20] Sjögren, P. (2011) Hospitalisation Associated with a Deterioration in Oral Health. Evidence-Based Dentistry, 12, 48. http://dx.doi.org/10.1038/sj.ebd.6400793

[21] Corsalini, M., Rapone, B., Grassi, F.R. and Di Venere, D. (2010) A Study on Oral Rehabilitation in Stroke Patients: Analysis of a Group of 33 Patients. Gerodontology, 27, 178-182.

[22] Vigild, M. (1990) Oral health in Institutionalized Elderly. Tandlaegebladet, 94, 168-194.

[23] Henry, R.G. and Geridan, B. (1994) Delivering Dental Care to Nursing Home and Homebound Patients. Dental Clinics of North America, 38, 537-551.

[24] Buds-Jorgensen, E. (1990) Etiology, Pathogenesis, Therapy, and Prophylaxis of Oral Yeast Infections. Acta Odontologica Scandinavica, 48, 61-69. http://dx.doi.org/10.3109/00016359009012735

[25] Peltola, P., Vehkalahti, M.M. and Simoila, R. (2007) Effects of 11-Month Interventions on Oral Cleanliness among the Long-Term Hospitalised Elderly. Gerodontology, 24, 14-21. http://dx.doi.org/10.1111/j.1741-2358.2007.00147.x

[26] Huskinson, W. and Lloyd, H. (2009) Oral Health in Hospitalised Patients: Assessment and Hygiene. Nursing Standard, 23, 43-47. http://dx.doi.org/10.7748/ns2009.05.23.36.43.c6969 
Scientific Research Publishing (SCIRP) is one of the largest Open Access journal publishers. It is currently publishing more than 200 open access, online, peer-reviewed journals covering a wide range of academic disciplines. SCIRP serves the worldwide academic communities and contributes to the progress and application of science with its publication.

Other selected journals from SCIRP are listed as below. Submit your manuscript to us via either submit@scirp.org or Online Submission Portal.
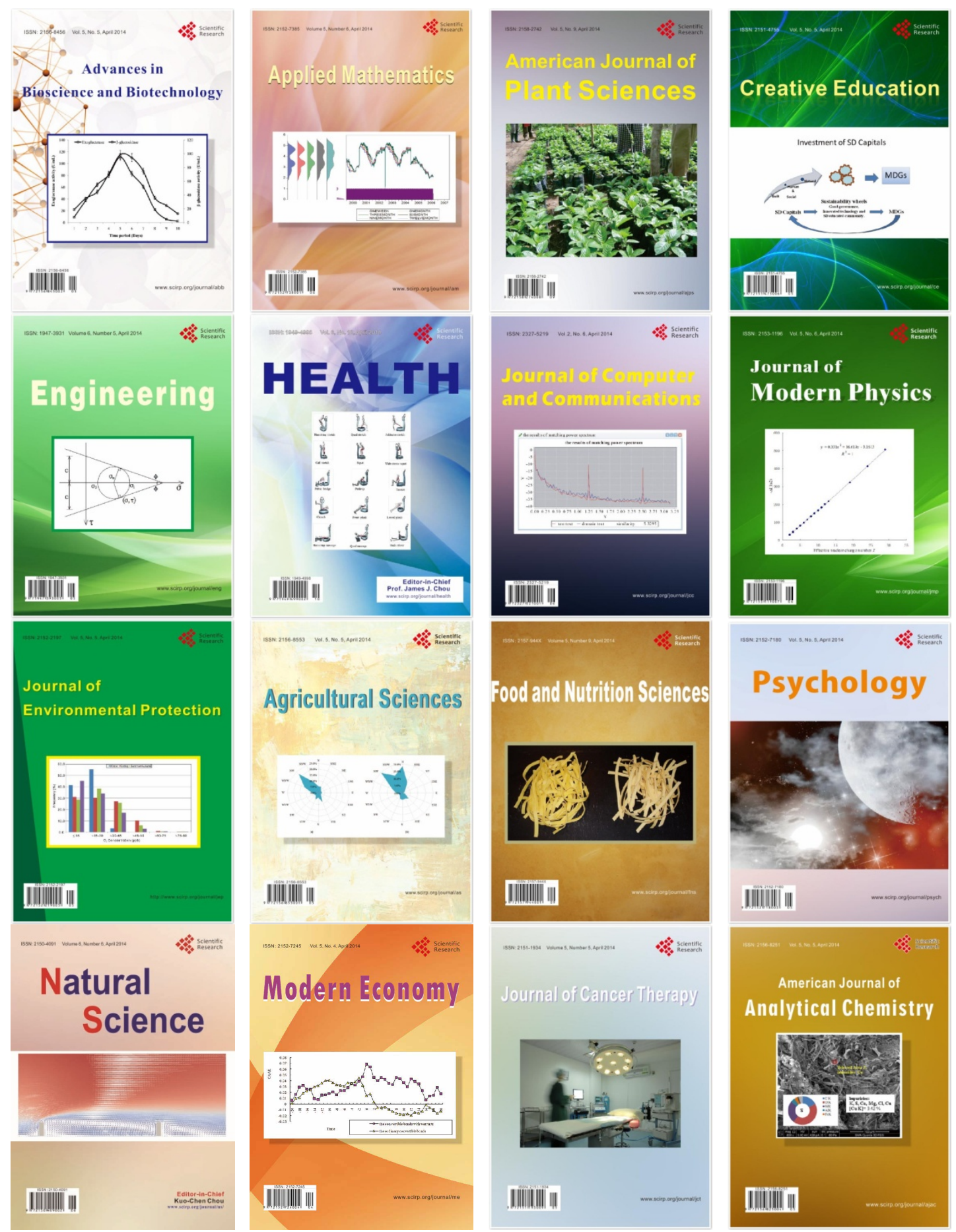